\title{
Odontometric and Skull Anthropometric Parameters as a Forensic Tool in Stature Estimation: A Cross-sectional Analysis
}

\author{
${ }^{1}$ Shailesh M Gondivkar, ${ }^{2}$ Amol R Gadbail, ${ }^{3}$ Priyanka R Vedpathak, ${ }^{4}$ Sachin Sarode \\ ${ }^{5}$ Gargi Sarode, ${ }^{6}$ Mugdha Mankar (Gadbail), ${ }^{7}$ Shankargouda Patil
}

\begin{abstract}
Background: The aim of the study was to evaluate the relation between height of an individual with the circumference of skull and combined mesiodistal width (CMDW) of the permanent maxillary anterior teeth in forensic and medicolegal investigations.

Materials and methods: In this study, 100 persons were evaluated. Mesiodistal widths of the permanent maxillary anterior teeth and height and circumference of the skull were measured. Linear regression analysis was used for the known heights of the combined data and data for males and females against the odontometric and anthropometric variables.
\end{abstract}

Results: Highly significant correlation was observed between height and other parameters for combined data and data for males. There was statistically significant difference between equation relating height to the CMDW of the maxillary anterior teeth and equation relating height to head circumference.

Conclusion: It can be stated that the skull with teeth may provide accurate clues to stature from an individual's fragmentary remains and thus provide a reliable method of estimation of height from skeletal remains during forensic investigations.

Clinical significance: Odontometric parameters along with regression equations may be used as a supplementary approach for stature estimation, especially in situations of unavailability of extremities. In the advancement of field of forensic odontology, skull anthropometry including maxillary extent, mesiodistal dimension of anteriors, and circumference of the skull are beneficial for stature estimation.

${ }^{1}$ Department of Oral Medicine and Radiology, Government Dental College \& Hospital, Nagpur, Maharashtra, India

${ }^{2}$ Department of Dentistry, Indira Gandhi Government Medical College \& Hospital, Nagpur, Maharashtra, India

${ }^{3}$ Department of Oral Medicine and Radiology, Mahatma Gandhi Vidyamandir's Karmaveer Bhausaheb Hiray Dental College \& Hospital, Nashik, Maharashtra, India

${ }^{4,5}$ Department of Oral and Maxillofacial Pathology, Dr. D.Y. Patil Dental College \& Hospital, Dr. D.Y. Patil Vidyapeeth, Pune Maharashtra, India

${ }^{6}$ Department of Orthodontics, Swargiya Dadasaheb Kalmegh Smruti Dental College \& Hospital, Nagpur, Maharashtra, India

${ }^{7}$ Division of Oral Pathology, Department of Maxillofacial Surgery and Diagnostic Sciences, College of Dentistry, Jazan University Jazan, Kingdom of Saudi Arabia

Corresponding Author: Sachin Sarode, Department of Oral and Maxillofacial Pathology, Dr. D.Y. Patil Dental College \& Hospital, Dr. D.Y. Patil Vidyapeeth, Pune, Maharashtra, India Phone: +919922491465, e-mail: drsachinsarode@gmail.com
Keywords: Forensic, Identification, Skull, Stature, Teeth.

How to cite this article: Gondivkar SM, Gadbail AR, Vedpathak PR, Sarode S, Sarode G, Mankar M, Patil S. Odontometric and Skull Anthropometric Parameters as a Forensic Tool in Stature Estimation: A Cross-sectional Analysis. World J Dent 2017;8(3):202-206

Source of support: Nil

Conflict of interest: None

\section{INTRODUCTION}

Many times, mutilated bodies or just fragmentary remains are presented for medicolegal examination. However, at times, only skull or facial remains are brought for examination as well as identification. There are certain accidents, such as fire disaster, attack by wild animals in deep forests, aircraft or road accident, and terrorist attack, which cause difficulty in identification. In such cases, identification by fingerprints or facial recognition methods can be difficult or even impossible, and thus, a postmortem record is created by a forensic dentist to identify the victim by determining the age, stature, ancestry, sex, and socioeconomic class. ${ }^{1}$ Under such circumstances, it is important to establish the identity of the inanimate. Stature (height of a person in the upright posture) is an important anthropometric parameter for establishing the identity. ${ }^{2}$ Since it is quite obviously visible, stature can be used to determine the physical identity of an individual. ${ }^{3,4}$ Many scientists had done work on various bones of the human skeleton for the reestablishment of stature. ${ }^{5}$ Accurate biological correlation of stature is associated with some body parts, such as extremities, head, trunk, and vertebral column. ${ }^{6}$ Sections of long bones have been used for the determination of stature with great accuracy by forensic anthropologists in extreme situations, where the other evidence is incomplete and fragmented. ${ }^{7}$ Most of the times, all the bones of the individual are usually not retrieved, during forensic and archaeological excavation, and in mutilated body, head will be amputated from the trunk. ${ }^{8}$ Long bones were the mostly used skeletal remains to establish stature identification, ${ }^{9,10}$ based on the principle of positive correlation between various long bones and stature. ${ }^{11}$ Few studies have been carried out correlating various odontometric parameters with 
the height of an individual. ${ }^{8}$ In prosthodontics, there are indices showing relationship of odontometric parameters to cranium. ${ }^{12}$ Furthermore, there is a relationship between the head circumference $(\mathrm{HC})$ and the combined mesiodistal width (CMDW) of the maxillary anterior teeth. ${ }^{13}$ There are very few literature estimating the data about the height from an odontometric parameter. The studies showing correlation of tooth dimensions with height as ratios or regression equations are occasional. ${ }^{12,14}$ Teeth are an excellent material for forensic investigation as odontologic, anthropological, and genetic. The teeth and skull measurements have several advantages over other body parts as the anatomical landmarks are standard, well developed, and easy to locate. ${ }^{1}$ Considering these facts, our study was aimed to investigate relation between height of a person with the circumference of skull and CMDW of the maxillary anterior teeth.

\section{MATERIALS AND METHODS}

This study was conducted in the Department of Oral Medicine and Radiology, Mahatma Gandhi Vidyamandir's Karmaveer Bhausaheb Hiray Dental College \& Hospital, Nashik, India. Approval of the Institutional Ethical Committee was obtained before commencement of the study. A total of 100 individuals were randomly selected, comprising 50 males and 50 females. All the individuals were in the age range of 20 to 40 years as the stature is accepted as adult one and multiplication factor remains near constant above 18 years of age. ${ }^{15}$ Individuals who fulfilled following mentioned inclusion criteria were recruited in the study: (1) Fully erupted intact permanent maxillary anterior teeth with sound periodontal condition and satisfactory alignment, (2) individuals without any clinical evidence or history of cleft palate, trauma, crown restorations, orthodontic treatment or orthognathic surgery, and surgery of the skull, (3) individuals not having any of the developmental disorders, endocrinal disorders, metabolic disorders, and history of prolonged illness. All the recruited individuals were informed about the study, and written consent was obtained (Fig. 1).

With the help of digital Vernier caliper, the greatest mesiodistal width of crown of six maxillary anterior permanent teeth, i.e., right central incisor, right lateral incisor, right canine, left central incisor, left lateral incisor, and left canine, was measured directly on the individuals between anatomic contact points of each tooth. This distance was measured accurately by holding digital Vernier caliper parallel to the occlusal plane so that the interproximal areas can be accessed easily. Mesiodistal widths of crowns of the six maxillary anterior teeth were then added to achieve CMDW. Fronto-occipital HC and height were recorded. For measuring maximal fronto-occipital circumference, a nonstretchable measuring plastic tape

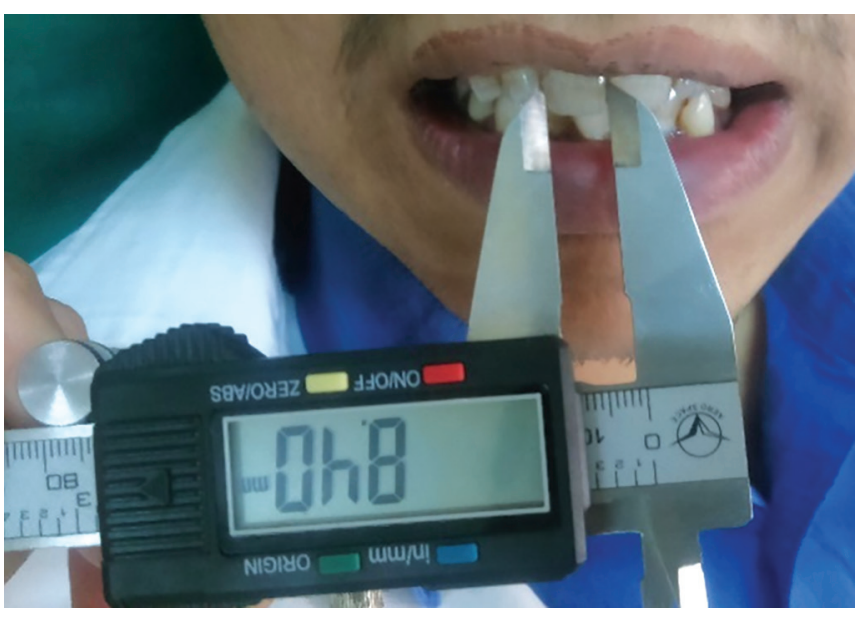

Fig. 1: Mesiodistal crown width measurement with digital Vernier's Caliper

(calibrated in $\mathrm{mm}$ ) was placed on the occipital prominence and the supraorbital ridges. Care was taken to view each individual laterally to make sure that the measuring tape was placed properly. The height of each individual was measured as vertical distance between the vertex and the floor with the help of a standard anthropometer. On a horizontal plane, the individuals were instructed to stand erect barefooted. Anthropometer was placed in straight vertical position behind the individual with head oriented in Frankfort horizontal plane and shoulder blocks and buttocks touching the vertical limb of the instrument. The movable rod of the anthropometer was brought in contact with vertex in the midsagittal plane. To reduce the discrepancies of diurnal variation, all these measurements were recorded by only one observer between $10 \mathrm{am}$ and 1 pm only. The above-mentioned measurements were recorded three times, and their mean value was calculated accordingly to achieve a final measurement.

All the obtained data were then entered into Microsoft Excel and analyzed using Statistical Package for the Social Sciences software version 20. Karl Pearson's correlation coefficient of CMDW and HC with stature was obtained. For each parameter, regression equations were derived using simple linear regression analysis.

\section{RESULTS}

Table 1 shows the descriptive statistics for the four measurements recorded in the sample. Statistically significant sexual dimorphism was recorded from most of the measurements studied ( $\mathrm{p}<0.001)$. The mean CMDW was noticed to be $49.65 \pm 2.51$ and $48.28 \pm 2.41$ in males and females respectively. Males in the group were observed to be tall as compared with females (174.4 \pm 73.05 vs $1588.2 \pm 60.09)$. A highly significant difference $(p<0.001)$ was recorded in $\mathrm{HC}$ in males and females. Although the coefficient was small, we found a statistically significant correlation between the two when CMDW of the 
Table 1: Descriptive statistics for the parameters recorded for males and females

\begin{tabular}{llllll}
\hline Parameters & Gender & $n$ & Mean \pm SD & SEM & $p$-value \\
\hline $\mathrm{RCI}$ & Male & 50 & $8.9720 \pm 0.44678$ & 0.06318 & 0.024 \\
& Female & 50 & $8.7660 \pm 0.45158$ & 0.06386 & \\
$\mathrm{RLI}$ & Male & 50 & $7.2500 \pm 0.67317$ & 0.09520 & 0.083 \\
& Female & 50 & $7.0320 \pm 0.56908$ & 0.08048 & \\
$\mathrm{RC}$ & Male & 50 & $8.6120 \pm 0.49842$ & 0.07049 & 0.007 \\
& Female & 50 & $8.3060 \pm 0.61293$ & 0.08668 & \\
$\mathrm{LCl}$ & Male & 50 & $8.9620 \pm 0.42661$ & 0.06033 & 0.059 \\
& Female & 50 & $8.7980 \pm 0.43070$ & 0.06091 & \\
$\mathrm{LLI}$ & Male & 50 & $7.2520 \pm 0.66032$ & 0.09338 & 0.174 \\
& Female & 50 & $7.0840 \pm 0.56111$ & 0.07935 & \\
$\mathrm{LC}$ & Male & 50 & $8.6060 \pm 0.49256$ & 0.06966 & 0.007 \\
& Female & 50 & $8.2980 \pm 0.61561$ & 0.08706 & \\
$\mathrm{HC}$ & Male & 50 & $542.42 \pm 18.47899$ & 2.61332 & 0.000 \\
& Female & 50 & $527.18 \pm 19.10411$ & 2.70173 & \\
Height & Male & 50 & $1749.4 \pm 73.05743$ & 10.33188 & 0.000 \\
& Female & 50 & $1588.2 \pm 60.09992$ & 8.49941 & \\
CMDW & Male & 50 & $49.6540 \pm 2.51957$ & 0.35632 & 0.007 \\
& Female & 50 & $48.2840 \pm 2.41672$ & 0.34178 & \\
\hline
\end{tabular}

RCl: Right central incisor; RLI: Right lateral incisor; RC: Right canine; LCl: Left central incisor; LLI: Left lateral incisor; LC: Left canine; CMDW: Combined mesiodistal width; HC: Head circumference; SD: Standard deviation; SEM: Standard error of mean maxillary teeth was plotted against height. When HC was regressed to the height for the combined data and data for males, a higher correlation was noticed. When two measurements were added and correlated to the height, the gradient of the trend line improved indicating elevated correlation. Thus, a high correlation was seen when height was regressed against addition of CMDW and $\mathrm{HC}$. The regression equations are derived as listed in Table 2. Thus, we can state that this category provided the most reliable stature estimates. Results of this study showed that most male and combined data parameters had a positive correlation with the stature.

\section{DISCUSSION}

The identification of a person, especially from fragmentary remains, has become an important aspect in forensic investigations. The identity of an unknown individual can be estimated using age, sex, and stature. However, considering only the stature, identification of an individual has become easy because then the missing persons of only that stature need to be considered. ${ }^{16}$ Teeth are resistant to damage and odontometric parameters remain

Table 2: Statistical analysis with derivation of regression equation of stature for each parameter

\begin{tabular}{|c|c|c|c|c|c|}
\hline Parameter studied & Group & $r$ & $m x+c$ & SEE value & $p$-value \\
\hline \multirow[t]{3}{*}{$\mathrm{RCl}$} & Combined & 0.238 & $54.39 x+2372.83$ & 0.4478 & 0.017 \\
\hline & Males & 0.239 & $39.07 x+1398.87$ & 0.4383 & 0.095 \\
\hline & Females & 0.059 & $-7.91 x+1657.53$ & 0.4555 & 0.682 \\
\hline \multirow[t]{3}{*}{ RLI } & Combined & 0.158 & $26.23 x+2962.99$ & 0.6250 & 0.117 \\
\hline & Males & 0.069 & $7.52 x+1694.88$ & 0.6785 & 0.633 \\
\hline & Females & 0 & $-0.98 x+1595.09$ & 0.575 & 0.949 \\
\hline \multirow[t]{3}{*}{$\mathrm{RC}$} & Combined & 0.216 & $39.20 x+2674.42$ & 0.5660 & 0.031 \\
\hline & Males & 0.109 & $-15.98 x+1887.01$ & 0.5006 & 0.451 \\
\hline & Females & 0.019 & $13.69 x+1474.49$ & 0.6132 & 0.333 \\
\hline \multirow[t]{3}{*}{$\mathrm{LCl}$} & Combined & 0.060 & $58.89 x+2291.72$ & 0.4234 & 0.014 \\
\hline & Males & 0.229 & $39.23 x+1397.82$ & 0.4196 & 0.110 \\
\hline & Females & 0.070 & $9.82 x+1501.81$ & 0.4341 & 0.627 \\
\hline \multirow[t]{3}{*}{ LLI } & Combined & 0.019 & $23.68 x+2998.13$ & 0.6126 & 0.168 \\
\hline & Males & 0.033 & $3.60 x+1723.29$ & 0.6668 & 0.822 \\
\hline & Females & 0.081 & $8.68 x+1526.71$ & 0.5651 & 0.575 \\
\hline \multirow[t]{3}{*}{ LC } & Combined & 0.050 & $40.58 x+2651.64$ & 0.5642 & 0.026 \\
\hline & Males & 0.880 & $-13.10 x+1862.13$ & 0.4957 & 0.542 \\
\hline & Females & 0.136 & $13.29 x+1477.92$ & 0.6162 & 0.346 \\
\hline \multirow[t]{3}{*}{ CMDW } & Combined & 0.256 & $10.51 x+2308.36$ & 2.4785 & 0.010 \\
\hline & Males & 0.069 & $2.011 x+1649.566$ & 2.5396 & 0.632 \\
\hline & Females & 0.88 & $2.19 x+1482.46$ & 2.4323 & 0.543 \\
\hline \multirow[t]{3}{*}{$\mathrm{HC}$} & Combined & 0.427 & $2.21 x+973.78$ & 18.365 & 0.000 \\
\hline & Males & 0.411 & $1.62 x+870.68$ & 17.021 & 0.003 \\
\hline & Females & 0.017 & $0.05 x+1561.84$ & 19.299 & 0.908 \\
\hline \multirow[t]{3}{*}{$\mathrm{CMDW}+\mathrm{HC}$} & Combined & 0.442 & $2.02 x+871.77$ & 18.9392 & 0.000 \\
\hline & Males & 0.41 & $0.83 x+501.21$ & 17.4415 & 0.003 \\
\hline & Females & 0.027 & $1.83 x+438.83$ & 20.00 & 0.852 \\
\hline
\end{tabular}

RCI: Right central incisor; RLI: Right lateral incisor; RC: Right canine; LCl: Left central incisor; LLI: Left lateral incisor; LC: Left canine; CMDW: Combined mesiodistal width; HC: Head circumference; SEE: Standard estimate of error; r: Correlation with observed stature; $y=m x+c ; y$ : Stature; m: Intercept; $x$ : Variable; c: Slope 
constant over time. The methods of identification using teeth have various advantages as teeth are well defined and easy to locate standard anatomical landmarks. ${ }^{17}$ Different scientists from all over the world used different bones of human skeleton right from femur to metacarpals to predict stature. ${ }^{18}$ In situations of unavailability of these bones, recording of other body parts can also be useful to estimate body height. The dimensions of tooth and skull are also genetically determined as other bones of the body. ${ }^{19}$ Their measurements are unique for each race and geographical area since they are based on environmental variations as well. ${ }^{20}$ Studies related to the stature estimation from odontometric parameters are circumscribed in Indian population. Therefore, the present research aimed to provide the valuable data pertaining to the correlation of stature with tooth for Indians.

A medical examiner may never know the type of demonstration presented to him or her for forensic examination. Such requirements can be met using new methods based on sound principles. Thus, there is a need to investigate any possible significant correlation of stature with teeth and skull dimensions. However, such a study can gain significance when multiple parts of a mutilated body or only isolated facial structure presents for forensic examination. ${ }^{21}$ Prabhu et $\mathrm{al}^{22}$ performed a study in 2013 on 95 adult individuals ( 47 females and 48 males) using buccolingual and mesiodistal measurements of all teeth, except third molars and stature estimates. They suggested that the dentition might be used as a supplement to more valid predicator of stature as they observed moderately significant correlation between the two. In contrast, no correlation between tooth width and stature was noted by Filipsson and Goldson ${ }^{14}$ in early 1963 in Swedish population. Smaller sample size or difference in ethnicity may have shown this low correlation.

Osteometry seems to be the more favored and effective method in determining sex and race to an extent. ${ }^{23} \mathrm{In}$ this study, on plotting individual measurements of combined data against height, we found a highest correlation. In this modern era, the increased use of the regression formulae has definitely enhanced the precision of stature estimation. In addition, adjoining the odontometric and craniometric parameters has elevated the correlation with the stature prediction. Thus, analysis of the combined data showed a statistically significant correlation. The small sample size and nonhomogenous sampling may be responsible for inadequate outcomes procured from male and female statistics.

In this study, odontometry alone was noticed to be unreliable in stature estimation. This study provides a statistically effective technique to achieve accurate clues of stature as well as conspicuous need of gender determination from fragmentary remains of humans. It was also observed that circumference of the skull and CMDW of the maxillary anterior teeth were statistically significant in correlation with height. Similar results were reported by Gupta et al. ${ }^{1}$ However, few previous studies showed statistically insignificant correlation of mesiodistal dimensions of maxillary anteriors with height. Few limitations of this study were no use of ethnic or regional-specific regression formulae and selection of maxillary anterior teeth only. Further research with larger samples should be carried out in such a way that the validity of stature estimation from odontometric parameters should be upgraded.

\section{CONCLUSION}

The results of this study suggest that teeth dimensions combined with skull measurements may definitely be a reliable tool in stature estimation of an individual. Thus, odontometric parameters along with regression equations may be used as a supplementary approach for stature estimation, especially in situations of unavailability of extremities. In the advancement of field of forensic odontology, skull anthropometry including maxillary extent, mesiodistal dimension of anteriors, and circumference of the skull are beneficial for stature estimation.

\section{REFERENCES}

1. Gupta A, Kumar K, Shetty DC, Wadhwan V, Jain A, Khanna KS. Stature and gender determination and their correlation using odontometry and skull anthropometry. J Forensic Dent Sci 2014 May;6(2):101-106.

2. Stedman TL. Stedman's Medical Dictionary. Baltimore: Lippincott Williams and Wilkins; 2000. p. 211.

3. Kumar J, Chandra L. Estimation of stature using different facial measurements among the Kabui Naga of Imphal valley, Manipur. Anthropologist 2006;8(1):1-3.

4. Jadav HR, Shah GV. Determination of personal height from the length of head in Gujarat region. J Anat Soc India 2004;53:20-21.

5. Holland TD. Estimation of adult stature from fragmentary tibias. J Forensic Sci 1992 Sep;37(5):1223-1229.

6. Wells LH. Estimation of stature from long bones: a reassessment. J Forensic Med 1959;6:171-177.

7. Udhaya K, Saraladevi KV, Sridhar J. Regression equation for estimation of length of humerus from its segments: a South Indian population study. J Clin Diagn Res 2011;5:783-786.

8. Kalia S, Shetty SK, Patil K, Mahima VG. Stature estimation using odontometry and skull anthropometry. Indian J Dent Res 2008 Apr-Jun;19(2):150-154.

9. Hasegawa I, Uenishi K, Fukunaga T, Kimura R, Osawa M. Stature estimation formulae from radiographically determined limb bone length in a modern Japanese population. Leg Med (Tokyo) 2009 Nov;11(6):260-266.

10. Didia BC, Nduka EC, Adele O. Stature estimation formulae for Nigerians. J Forensic Sci 2009;54(1):20-21.

11. Simmons T, Jantz RL, Bass WM. Stature estimation from fragmentary femora: a revision of the Steele method. J Forensic Sci 1990 May;35(3):628-636. 
12. Veeraiyan DN, Ramalingam K, Bhat V. Textbook of prosthodontics. New Delhi: Jaypee Brothers Medical Publishers Ltd.; 2003. p. 169.

13. Hamid R, Master SB, Udani TM. Facial measurements and their relationship to the mesio-distal dimensions of the maxillary anterior teeth. J Indian Dent Assoc 1979;51:303-306.

14. Filipsson R, Goldson L. Correlation between tooth width, width of the head, length of the head, and stature. Acta Odontol Scand 1963;21:359-365.

15. Roche AF, Davila GH. Late adolescent growth in stature. Pediatrics 1972 Dec;50(6):874-880.

16. Dahlberg AA. Dental traits as identification tools. Dent Program 1963;3:155-160.

17. Whittaker DK, MacDonald DG. A Colour Atlas of forensic dentistry. 1st ed. England: Wolfe Medical Publications Ltd.; 1989. p. 58-66.

18. Sheta A, Hassan M, Elserafy M. Stature estimation from radiological determination of humerus and femur lengths among a sample of Egyptian adults. Bull Alex Fac Med 2009;45:479-486

19. William PL, Bannister LH, Berry MM, Collins P, Dyson M, Dussk JE, Ferguson MWJ. Gray's anatomy. 38th ed. Philadelphia (PA): ELBS/Churchill Livingstone; 1995. p. 607-610.

20. Bermúdez de Castro JM, Nicolas ME. Posterior dental size reduction in hominids: the Atapuerca evidence. Am J Phys Anthropol 1995 Apr;96(4):335-356.

21. Wankhede KP, Kamdi NY, Parchand MP, Anjankar VP, Bardale RV. Estimation of stature from maxillo-facial anthropometry in a central Indian population. J Forensic Dent Sci 2012 Jan;4(1):34-37.

22. Prabhu S, Acharya AB, Muddapur MV. Are teeth useful in estimating stature? J Forensic Leg Med 2013 Jul;20(5): 460-464.

23. Jason DR, Taylor K. Estimation of stature from the length of the cervical, thoracic, and lumbar segments of the spine in American whites and blacks. J Forensic Sci 1995 Jan;40(1):59-62. 